\title{
A Conceptual Design of Multi-Agent based Personalized Quiz Game
}

\author{
Martin M. Weng ${ }^{1}$, Ireti Fakinlede ${ }^{2}$, Fuhua Lin ${ }^{2}$, Timothy K. Shih ${ }^{3}$, Maiga Chang ${ }^{2}$ \\ ${ }^{1}$ Dept. of Computer Science and Information Engineering, Tamkang University, Taipei, Taiwan \\ ${ }^{2}$ School of Computing And Information Systems, Athabasca University, Athabasca, Canada \\ ${ }^{3}$ Dept. of Computer Science and Information Engineering, National Central University, Taoyuan, Taiwan \\ wmt25@hotmail.com,iretifa@yahoo.ca,fuhua.o.lin@gmail.com,timothykshih@gmail.com,maiga.chang@gmail.com
}

\begin{abstract}
This paper presents the conceptual design of a virtual 3D quiz game based on a multi-agent system (MAS) architecture aptly named QuizMASter. The QuizMASter supports formative assessment by providing adaptive testing and feedback using intelligent pedagogical agents within an immersive game-based virtual learning environment. This enables instructors to use assessment as a motivational tool within an entertaining context where students do not feel the usual pressures related to taking tests.
\end{abstract}

Keywords- multi-agent systems, immersive game-based virtual learning environments, formative assessment, quiz games

\section{INTRODUCTION}

Current trends in learning theories have encouraged the integration of intelligent agents within e-learning systems to meet new demands on learning management systems. While intelligent-agent-based-systems have existed for many years, recent surge in mainstream popularity has increased researchers' motivation to investigate its educational potential. While the concept of Game based learning (GBL) has been around for decades, it has recently received renewed interest from the research community due to the "Information Technology and Internet boom" [1]. Just like with edutainment and serious games, GBL offers a new marking direction for the implementation of agent technology, humancomputer interaction, multimedia interaction and ubiquitous computing [2]. Video games create intrinsic motivation through fantasy, control, challenge, curiosity and competition. Several commercially successful games such as strategy games, simulations, and role-playing games have been noted to implement sound learning, socializing, and interacting strategies which may be deliberately harnessed to equip instructional designers with new methods for engaging and motivating learners [1], [3]. The QuizMASter is designed to be an assessment tool that enables students to be tested within the context of a virtual 3D multiplayer game. It uses a format similar to that of a televised quiz game show [4]. It is implemented within a multiagent environment where agents are tasked with adaptively selecting and administering questions from a repository and then providing adequate feedback to the contestants and course instructors. The pedagogical model of the QuizMASter is based on the formative assessment approach that enables instructors to use assessment as a tool to motivate student learning [5].

In this paper we present a conceptual design and multiagent architecture for QuizMASter. The paper is organized as follows: Section 2 introduces our pedagogical framework; Section 3 presents the proposed system architecture; Section 4 describes a QuizMASter game scenario. Finally, Section 5 and 6 discusses the research issues, conclusions and future work.

\section{PEDAGOGICAL FRAMEWORK}

\section{A. Game-based Learning}

There has been a proliferation of game genres within the contemporary game market including: action, adventure, fighting, role playing, simulations, sports, strategy, etc [6]. Some games even span multiple genres. Some educators consider game based learning to be a powerful instructional model and several researchers have shown that certain genres i.e. strategy, simulation and role play can intrinsically support sound learning theories [1], [7]. Nevertheless, other studies have highlighted the issues relating to the integration of GBL into formal education such as the "transfer problem". While players may develop a number of skills and acquire certain knowledge during game play, it is uncertain if these can be transferred into a real environment [1].

The game objectives of the quiz game is directly related to its learning objectives i.e. assessment. The gaming context is similar to traditional assessment contexts; quiz games can be designed to support various assessment methods including: single choice, multiple choice, order, associate, match, gap match, inline choice, text entry, extend text, and hot text [8]. Therefore, quiz games should have no tensions between learning and gaming.

Quiz game shows, radio and televised, have always been a popular form of entertainment. Quiz game shows typically involve a small group of contestants that compete by answering questions presented by the game show host. The contestants score points by correctly answering questions before their opponents do and the contestant with the highest score is declared the winner. Since their first appearance in the 40's and 50's, televised quiz game shows have attracted a large and steady audience comprised of both the young and the old [9]. While educational games are often targeted at young people, it is likely that quiz show games will appeal to young learners as well as the older student.

\section{B. Formative Assessment}

"Historically, the main aim of measuring students' educational progress was to identify differences among students in order to rank them by achievement" [10] Traditional assessments are usually conducted at the end of a 
learning unit in a summative manner that makes pronouncements about a student's learning achievements. These assessment-centered learning environments skew the focus of instruction from learning towards simply passing the exam [5]. One study found that by year 4, fulltime undergraduate students only spend $5 \%$ of their time on learning, unrelated to assessment [11].

Due to the recent paradigm shift in education to support student-centered learning, there is an increased pressure for instructors to incorporate assessment within the learning process as a motivator and a way to generate just-in-time feedback that illuminates learner difficulties and enables instructors to modify their teaching strategies and apply appropriate remedial techniques [12]; these types of assessment is known as formative assessment supports 'assessment for learning' as opposed to the summative 'assessment of learning'. While commendable, formative assessment can be difficult to implement as it can be laborintensive and time-consuming; thus adding a considerable weight to the instructor's work load [11], [12].

\section{Pedagogical agents}

In e-learning, intelligent agents may be used to reduce staff work load. Agents can be used to communicate with learners, prompt and store learner attributes, characteristics, preferences, behavior and knowledge skill levels, as well as use machine learning to provide suitable, interesting and useful materials based on learners' profiles [13]. Agents can also be used to furnish instructors with informative and personalized feedback [14]. While the concept of these so called pedagogical agents has been well documented theoretically, their implementation within real learning systems is still at a nascent stage [15]

\section{Multi-Agent Systems}

A Multi-agent system (MAS) is a system composed of multiple interacting intelligent agents. The multi-agent approach addresses the issue of scalability by separating reasoning capabilities from other system functionality [15]. Tasks may also be distributed over several specialized agents that can achieve specified objectives through cooperation and negotiation. New services may be added to the system in the form of new agents without having to revise the entire system. Since agents only work when needed, resources maybe utilized efficiently.

\section{SYSTEM ARCHITECTURE}

The QuizMASter is designed in a format similar to a televised quiz game show; it relies on the friendly competition between contestants to motivate and engage students. Situated within a virtual environment, QuizMASter also leverages the benefits of an immersive environment to engage students' interests. The QuizMASter implements a multi-agent architecture which is comprised of pedagogical agents and a repository of possible game questions.

\section{A. Agents}

Within the context of a game, the pedagogical agents are tasked with adaptively selecting and administering questions from the repository and then providing adequate feedback to the contestants and course instructors as well as updating the QuizMASter's knowledge base. Question selection must be adequately challenging (i.e. not too hard, not too easy and not repetitive) and the game play (i.e. timing of questions, number of questions per round, how hints should be applied, and the total duration of the quiz) must also be designed so as to ensure that players have fun, remain motivated and interested in the game. Other pedagogical agents are responsible for maintaining each player's student model, and providing feedback while others act as contestants when there are not enough human players to make up a game ensuring that there are always opponents to challenge the human contestant.

\section{B. Knowledge domain}

This utilizes three databases for storing domain knowledge i.e. the game database used to store user game information (i.e. game ranking, game playing history, and game reward mechanism), the user database used to store related learner profiles and the learning materials database which is a repository of possible game questions.

\section{GAME SCENARIO}

In this section, we will describe a scenario of a QuizMASter game. A student called Peter logs-in to the LMS, and the LMS has an interface that connects to the QuizMASter's Virtual Learning Environment.

Peter registers (this is only done once the very first time that Peter sign's in) to play QuizMASter, the system collects valuable data about the Peter using pre-tests and questionnaires which are used to generate a profile for Peter by a user agent. Based on this profile the knowledge agent uses an algorithm to determine the Peter's knowledge/proficiency level. Peter is allowed to explore the virtual environment and be part of the audience of ongoing games. When he decides that he would like to play a game, the game agent uses Peter's proficiency level and preferences to determine the difficulty level, subject and co-contestants for a game. If there are no available human contestants at Peter's level NPCs are used to make up a group.

A game is comprised of a number of rounds. In each round, the knowledge agent utilizes an algorithm to determine the joint proficiency level of the group. Based on the algorithm's result the instructor agent selects a number of candidate questions from the repository. The host agent, just like the host in TV quiz game show presents the questions to the contestants. The host agent has an emotional aspect so as to interact with the contestants in a lively and engaging manner. 


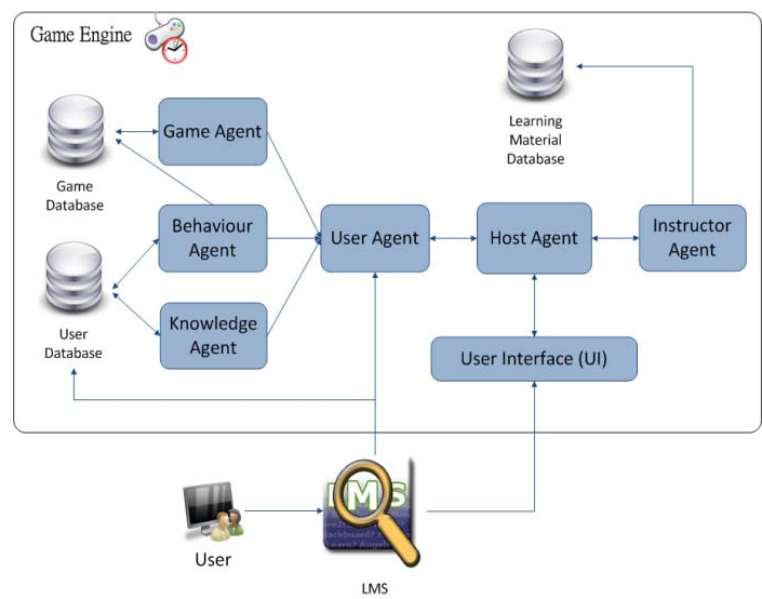

Figure 1: System Architecture

Contestants score points by correctly answering questions before their opponents [4] or before the timer runs out. In the context of a multiagent environment answering a question is accomplished using the Contract Net Protocol (CNP). The CNP has two stages: the propose stage and the contract stage. In the propose stage, the host agent as the initiator asks the contestants for the answer or "a proposal" to a question. The contestants can either respond with an answer/proposal or refuse to answer the question. In the contract stage, the host agent then sorts the answers according to correctness and response time. The contestant that sends the correct answer fastest is awarded a game point. The behavior agent collects the following information: response time, answers given, hints used, and score. This information is forwarded to the knowledge and user agents. The knowledge agent creates feedback about Peter's learning progress and the user agent updates the Peter's profile accordingly.

\section{RESEARCH QUESTIONS AND FURTHER WORK}

The main focus of this research is to:

1. Propose and implement new algorithms for the intelligent agent's reasoning, communication and interaction capability

2. Measure QuizMASter's effectiveness in increasing student motivation and performance compared to a control group being taught without QuizMASter.

3. Gather evidence that supports the claim that improvements in student achievement can be linked to the use of assessment information.

4. Prove that quiz show games have a high knowledge transfer i.e. how student performance in the game reflects success of learning process.

\section{CONCLUSION}

In this paper, we proposed the framework for a formative assessment tool that enables students to be tested within the context of a virtual 3D multiplayer game. QuizMASter leverages the advantages of friendly competition and virtual learning advantages and a multi-agent architecture. The system is comprised of six main agents and three databases used to manage game play, provide adaptive material and informative feedback. QuizMASter supports the current trends in student-centered learning. It is a valuable addition to the field of game-based learning for the purpose of delivering personalized and highly enjoyable and successful learning experiences to students.

\section{REFERENCES}

[1] Brom, C., Šisler, V., \& Slavík, R. (2010). Implementing digital gamebased learning in schools: Augmented learning environment of 'Europe 2045'. Multimedia Systems, 16(1), 23-41. doi:10.1007/s00530-0090174-0

[2] Lindley, C., \& Sennersten, C. (2008) Game Play Schemas: From Player Analysis to Adaptive Game Mechanisms. International Journal of Computer Games Technology, 2008(1), 47-53. Article ID 216784

[3] Dickey, M. (2005). Engaging by design: How engagement strategies in popular computer and video games can inform instructional design. Educational Technology Research and Development, 53(2), 67-83. Retrieved from http://dx.doi.org/10.1007/BF02504866

[4] Dutchuk, M., Muhammadi, K., \& Lin, F. (2009). QuizMASter - A multiagent game-style learning activity. In M. Hirose (Ed.), Learning by playing. game-based education system design and development ( $\mathrm{pp}$. 263-272) Springer Berlin / Heidelberg. doi:10.1007/978-3-642-03364332

[5] Shanshan Hu, \& Yonghua Xie. (2010). Improve student learning using online formative assessment system. Paper presented at the Education Technology and Computer (ICETC), 2010 2nd International Conference on, , 1 V1-253-V1-257.

[6] J-C. Hong, C-L. Cheng, M-Y. Hwang, C-K. Lee \& H-Y. Chang. (2009) Assessing the educational values of digital games. Journal of Computer Assisted Learning, 25(5), 423-437.

[7] Christiane Gresse, v. W. (2009, 03/01). To game or not to game? IEEE Software, 26, 92-94. Retrieved from http://doi.ieeecomputersociety.org/10.1109/MS.2009.54

[8] "IMS Question and Test Interoperability Implementation Guide Version 2.0 Final Specification". IMS GLC, 2005. Copyright 2005 by IMS GLC

[9] Lin, F., Kinshuk, \& Dutchuk, M. (2009) Multi-agent Architecture for Integrating Adaptive Features in Immersive 3D Virtual Learning Environments, MULE 2009

[10] Shute, V. J., \& Zapata-Rivera, D. (in press). Educational Measurement and Intelligent System. In E. Baker, B. McGaw, \& P. Peterson (Eds.), Third Edition of the International Encyclopedia of Education. Oxford, UK: Elsevier Publishers

[11] Smaill, C. R. (2005). The implementation and evaluation of OASIS: A web-based learning and assessment tool for large classes. Education, IEEE Transactions on, 48(4), 658-663.

[12] Wang, T. H. (2007). What strategies are effective for formative assessment in an e-learning environment? Journal of Computer Assisted Learning, 23(3), 171-186. Retrieved from http://dx.doi.org/10.1111/j.1365-2729.2006.00211.x

[13] Guzman, E., \& Conejo, R. (2005). Self-assessment in a feasible, adaptive web-based testing system. Education, IEEE Transactions on, 48(4), 688-695.

[14] Yin Bing, Lin Zhuying, \& Du Li. (2010) The Applications of MultiAgent Technology in Distance Education System. International Conference on Networking and Digital Society

[15] Yuh-Ming Cheng, Lih-Shyang Chen, Hui-Chung Huang, Sheng-Feng Weng, Yong-Guo Chen, \& Chyi-Her Lin. (2009). Building a general purpose pedagogical agent in a web-based multimedia clinical simulation system for medical education. Learning Technologies, IEEE Transactions on, 2(3), 216-225. 